Revista de Economia Política, vol. 41, n 3, pp. 611-632, julho-setembro/2021

\title{
Economia política das startups brasileiras: nova ordem em um cenário de turbulências
}

\author{
Political economy of Brazilian startups: \\ a new order in a turbulent scenario
}

ANITA KON*

\begin{abstract}
RESUMO: O artigo investiga as condições que permitem a criação e evolução das startups brasileiras no contexto de incertezas e instabilidade da economia do país desde 2010. Como base de análise, o trabalho examina as premissas da Teoria da Complexidade e da Teoria do Caos aplicadas à Economia. Em seguida são delineados os determinantes do surgimento e evolução destes modelos de negócios disruptivos no cenário mundial de crises e turbulência da década de 1990. A última seção trata da evolução destas empresas no Brasil até 2019, buscando explicar o comportamento dinâmico e evolutivo destes serviços, na conjuntura de instabilidade e desordem do país.

PALAVRAS-CHAVE: Inovação; startups; tecnologia; complexidade; Teoria do Caos.
\end{abstract}

ABSTRACT: The article investigates the conditions that enable the creation and evolution of Brazilian startups in the context of uncertainties and instability of the country's economy since 2010. The paper examines the premises of Complexity Theory and Chaos Theory applied to Economics. The study outlines the conditions for the emergence and evolution of these disruptive business models in the 1990s world scenario of crises and uncertainties. The last section deals with the evolution of these companies in Brazil until 2019, seeking to explain these services' dynamic behavior, in the country's conjuncture of instability and disorder.

KEYWORDS: Innovation; startups; technology; complexity; Chaos Theory.

JEL Classification: O; O14.

\section{INTRODUÇÃO}

O Brasil, desde 2014, passa por uma conjuntura econômica que alterna fases de estagnação e recessão, marcadas pela continuidade do desequilíbrio estrutural

\footnotetext{
* Professora Titular da PUC/SP. Coordenadora do Grupo de Pesquisas em Economia Industrial, Trabalho e Tecnologia do Programa de Estudos Pós-Graduados em Economia Política da Pontifícia Universidade Católica, São Paulo/SP, Brasil. E-mail: anitakon@pucsp.br. Orcid https://orcid.org/0000-0002-22174381. Submetido: 26/Agosto/2019; Aprovado: 6/Outubro/2020.
} 
das contas públicas, bem como por uma série de gargalos estruturais que limitam o crescimento e desestimulam o investimento produtivo. Neste cenário econômico de turbulências e instabilidade, as taxas de crescimento anuais dos vários setores, em sua grande maioria, se situam em torno de zero, alternando quedas ou crescimento insignificante. No entanto, neste contexto de estagnação, empresas como as denominadas startups, baseadas em plataformas digitais em seus modelos de operacionalização, têm atraído a atenção por apresentarem evolução considerável e constante, bem como uma dinâmica própria de investimentos, que rapidamente têm ganhado escala.

A Economia Política contemporânea é representada pela interligação entre teoria econômica e outros estudos interdisciplinares visando apreender como as instituições e os aspectos políticos influenciam a conduta dos agentes da sociedade diante do mercado em diferentes conjunturas. Sob esta ótica, este artigo busca uma reflexão sobre as características das empresas startups buscando entender as condições que permitiram sua criação e evolução, bem como a multiplicação de formas de atividades e de modelos de negócios diferenciados que as caracterizam, no contexto caótico da economia brasileira, em que as expectativas desfavoráveis são barreiras ao desenvolvimento econômico no cenário mais amplo da economia do país.

Para iniciar esta reflexão, este trabalho recorre a premissas teóricas ligadas à análise de sistemas econômicos complexos não lineares, visando estabelecer relações que existem entre o funcionamento destas novas empresas digitalizadas e os determinantes da conjuntura brasileira que expliquem o desenvolvimento acelerado destes serviços, no cenário do período. O corte teórico define primeiramente as premissas da Teoria Econômica da Complexidade e da Teoria do Caos, recorrendo a autores que definiram seus conceitos e sua aplicação à Economia.

$\mathrm{Na}$ seção seguinte são apresentadas as condições de criação e evolução, bem como as características destes modelos de negócios digitais disruptivos nos países mais avançados, no cenário mundial de contínuas crises desde a década de 1990. A última seção trata da evolução das startups brasileiras até 2019 , buscando na teoria a explicação para o comportamento dinâmico e progressivo destas empresas desde 2014, a partir de recursos humanos e financeiros ociosos e sem perspectivas outras de utilização na conjuntura de instabilidade e desordem.

\section{O CORTE TEÓRICO: A DINÂMICA DOS SISTEMAS ECONÔMICOS NO CENÁRIO DE TURBULÊNCIA}

\section{Não linearidade, complexidade e incerteza: da visão neoclássica à contemporânea}

A abordagem de Economia Política - utilizada para esta análise - é uma visão que tem passado por mudanças nos conceitos básicos à medida que a Economia $\mathrm{e}$ a Política mundial evoluem e percorrem períodos de transformação, como resultado do constante e crescente progresso tecnológico. A escolha do enfoque mais 
adequado aos objetivos desta investigação sobre as empresas digitais resultou da verificação das premissas que refletem o cenário econômico mundial na atualidade e os instrumentos de análise disponíveis para o estudo.

$\mathrm{Na}$ investigação econômica, como em outras áreas do conhecimento, durante vários séculos prevaleceram análises teóricas da realidade baseadas no raciocínio cartesiano com convicções mecanicistas, que sobreviveram com algumas revisões, criando um cenário simulado de segurança. Desde o pensamento de Descartes, no século XVII, é discutida a questão do conhecimento do homem como resultado da razão, que busca uma verdade que não possa ser posta em dúvida, o que foi expresso primeiramente nas premissas do denominado racionalismo cartesiano ou construtivista.

Assim, no racionalismo cartesiano, os processos sociais podem ser explicados sem considerar a abstração; as normas que não podem ser justificadas através da razão são rejeitadas pelos construtivistas, desde que a dedução lógica é a ação racional, perfeitamente formulada através da matemática. Esta abordagem foi reformulada posteriormente nas ideias de Bentham, que desenvolveu o conceito de utilitarismo nas premissas econômicas, concepção que constituiu a base das teorias neoclássicas. Nestas análises, o equilíbrio econômico é o objetivo buscado e será atingido em um tempo determinável pelos próprios agentes, fazendo-se uso de regras razoáveis. Este equilíbrio, constantemente buscado pelos atores, tem valor explanatório e embasa as explicações dos fenômenos sociais em geral (Mauerberg Jr., 2013).

A economia neoclássica baseada nas hipóteses centradas no utilitarismo trata os agentes com plena capacidade para computar informações e, no que se refere ao tratamento teórico que analisa a tomada de decisão da organização econômica a partir desta visão, a Microeconomia tradicional está particularmente preocupada com a análise da determinação da posição de equilíbrio estático nas empresas e nos mercados econômicos. As empresas operam como agentes de mercados, e a análise do equilíbrio do mercado é explicada de forma satisfatória a partir das condições de concorrência perfeita. Nesta visão, a análise centra-se nos modelos matemáticos abstratos, rigorosos e simplificados sobre as decisões da empresa (KON, 2016a).

Neste contexto, observa-se que, desde meados do século XX e mais intensamente no início do novo século, as variáveis envolvidas na dinâmica dos sistemas econômicos sofreram alterações profundas, tanto quantitativas quanto qualitativas como impacto do crescente avanço tecnológico e das turbulências políticas e sociais. Os resultados das "aproximações" em relação às previsões econômicas tornaram-se cada vez menos confiáveis. As regras do jogo alteram-se a cada instante, a quantidade avassaladora de informações, associadas ao progresso tecnológico surpreendente nas comunicações e possibilitadas por este avanço, fazem com que seja impossível controlar todas as variáveis (algumas previamente desconhecidas ou originadas pelo acaso) e, como consequência, as avaliações, ocorrências ou eventos planejados, frequentemente não acontecem conforme o previsto.

Assim, na atualidade determinadas hipóteses da microeconomia neoclássica vêm sendo criticadas e, entre elas, a que trata os agentes com plena capacidade 
para computar informações, questionando alguns dos resultados referentes ao equilíbrio geral, como a possibilidade de sua multiplicação entre as empresas e a capacidade de ser atingível em tempo razoavelmente determinado.

Por sua vez, as escolas de pensamento que resultaram das críticas ao equilíbrio neoclássico enfatizam especialmente o comportamento individual das empresas e dos mercados, durante os processos de crescimento, as implicações das transformações tecnológicas, a concentração e diversificação de produtos, que não se aplicam nas condições de concorrência perfeita, e a relevância das condições institucionais específicas que interferem no sistema econômico. Neste contexto, o progresso tecnológico não é exógeno ao modelo de produção da empresa e torna-se endogenamente incorporado às decisões dos agentes de crescimento.

A partir disto, os modelos preditivos neoclássicos existentes se mostram incompletos, baseados em uma representação de realidade menos complexa, onde as variáveis envolvidas nos processos ocorrentes permitem tratar os sistemas onde são aplicados como se fossem esquemas aproximadamente lineares. Os resultados obtidos também são aproximadamente corretos, deixando de fora elementos que, embora consideravelmente influentes, não se enquadram no padrão modelado.

Com base no pensamento de Hayek, entre as críticas à racionalidade cartesiana da economia neoclássica ressalta-se a que se refere ao fato de que os resultados do conjunto de ações dos agentes que buscam individualmente o equilíbrio não é simplesmente a agregação dos resultados individuais. Isto se verifica porque, da conexão entre estes atores que interagem entre si e com o ambiente, resulta um sistema complexo, pois os indivíduos não podem ser homogeneizados como se tivessem um comportamento idêntico e previsível. Estes sistemas apresentam uma dinâmica não linear e operante fora do equilíbrio, com agentes heterogêneos dotados de racionalidade limitada, vinculados por estruturas e instituições sociais, sendo os efeitos macroeconômicos resultados de ações microeconômicas (Mauerberg Jr., 2013). O estudo destes sistemas em Economia resultou em preceitos teóricos reunidos na Teoria da Economia da Complexidade, focalizada na não linearidade do comportamento de certos fenômenos.

Assim, a ideia de complexidade em Economia, trata destes sistemas complexos em que uma de suas partes influencia as demais envolvidas no mesmo sistema; estuda o fenômeno fora do equilíbrio, no qual os agentes econômicos ajustam continuamente seu comportamento. Estes estudos analisam cada caso distintamente, não utilizando modelos genérico-analíticos, mas valem-se de uma abordagem computacional que capta as relações entre os fenômenos e não sua constituição. Dessa forma, ampliam as possibilidades de teorização da complexidade (Mauerberg Jr., 2013).

Neste contexto, a realidade é visualizada como não linear, caótica, fractal, catastrófica e difusa e deve ser vista de forma não somente quantitativa, mas, principalmente, qualitativa. A nova abordagem busca um entendimento atualizado desta Economia visualizada como complexa, composta de sistemas interconectados.

O economista W. Brian Arthur (2014), um dos fundadores da Teoria da Complexidade, mostra que a economia neoclássica é insuficiente para explicar a reali- 
dade, que nunca atinge um estado de equilíbrio e, neste sentido, a complexidade se volta para a análise do funcionamento dos sistemas descentralizados, que são compostos por um número muito grande de agentes individuais que funcionam de modo não equilibrado. $\mathrm{O}$ autor salienta que esta abordagem oferece uma estrutura diferente para o pensamento econômico e não simplesmente uma extensão da lógica da teoria tradicional, pois a nova visão não se refere simplesmente à introdução do comportamento dos agentes aos modelos padrões anteriores, porém é uma forma diversa de observar a economia. Argumenta que nesta abordagem as ações e estratégias estão em constante evolução, o tempo assume importante papel, e os elementos estruturais da economia estão constantemente se formando e reformando, num contexto em que os fenômenos estão fora dos padrões da análise do equilíbrio.

Nesta abordagem, o não equilíbrio é gerado endogenamente, devido a duas razões fundamentais: a incerteza e a constante inovação tecnológica. À medida que a tecnologia se transforma os aspectos evolucionários, bem como a incerteza na tomada de decisão, aumentam, o que implica a ausência do equilíbrio. A mudança na abordagem econômica, portanto, é uma parte de uma transformação mais ampla na ciência em si, pois as ciências, inclusive a Matemática, estão se tornando mais baseadas em processos evolutivos e em algoritmos e menos em equações lineares e cartesianas, na busca de explicar os comportamentos não lineares, que geram incertezas (Arthur, 2014, p. 19).

No cenário de complexidade e incertezas, composto de sistemas interconectados, a busca do entendimento atualizado da economia encontra na Teoria do Caos (TC) premissas que podem servir de base para a melhor compreensão da tomada de decisão dos agentes. Alguns economistas recorrem à TC na busca da explicação das trajetórias efetivas observadas na Economia, caracterizadas por instabilidades diversas, porém verificando que, de alguma forma, tais instabilidades, desvios e imperfeições preservam a ordem fundamental do sistema, descrita por sua norma. Esta teoria trata do dilema entre ordem e desordem na Economia (Carvalho, 1994).

\section{Subsídios da Teoria do Caos à Economia: nova ordem na desordem}

Como visto, a análise teórica do funcionamento sistêmico das relações econômicas passa de paradigmas baseados em processos lineares e estáticos para a visão de sistemas complexos e dinâmicos, baseados em processos caóticos e não lineares. Como observava Joseph Alois Schumpeter (1961), em um nível micro, uma economia eficiente está constantemente se reajustando, otimizando as inter-relações entre inovação e "destruição criadora", resultando em uma mutação industrial, que revoluciona a estrutura econômica, destruindo a forma anterior de organização e criando uma nova forma. Assim, são observados processos caóticos na Economia, quando esta experimenta uma inabilidade de sincronizar estas inter-relações produtivas e, como consequência, alternam-se períodos de elevados investimentos com inovação acelerada com períodos de baixos investimentos e estagnação econômica. 
O precursor dos estudos sobre os fenômenos incertos em sistemas caóticos e da relevância do acaso nos resultados dos processos determinísticos de eventos naturais ou programados foi o matemático e meteorologista Edward Lorenz. A partir de seus estudos sobre a previsão meteorológica com a utilização de instrumentos matemáticos, este autor publica em 1963 as premissas do comportamento aleatório dos sistemas complexos e dinâmicos não lineares, cujo estado futuro é difícil de prever (Lorenz, 1996). Estas análises deram origem à Teoria do Caos, que utiliza sistemas de equações não lineares para explicar os fenômenos dinâmicos que são tão complexos que podem ter a aparência de completamente aleatórios.

Lorenz estabelece o princípio da "sensibilidade às condições iniciais" da evolução dos sistemas caóticos, conhecido como o Efeito Borboleta, que explica que condições iniciais ligeiramente diferentes nestes sistemas podem se desenvolver em situações consideravelmente diferentes como resultado. A ideia central estabelece que uma pequena mudança no início de um evento qualquer pode trazer consequências enormes e absolutamente desconhecidas no futuro e, dessa forma, tais eventos seriam praticamente imprevisíveis ou caóticos. Assim, estes sistemas complexos e dinâmicos não deixam de ser deterministas, mas apresentam um fenômeno de instabilidade resultante da sensibilidade às condições iniciais, com a propriedade de recorrência que conduz à instabilidade em longo prazo. Pequenos acasos e interferências que modificam sua trajetória formam uma estrutura caótica e imprevisível (Lorenz,1996).

Dessa maneira, a Teoria do Caos - aplicada à Economia - revela quais seriam as dificuldades na elaboração de previsões teóricas e empíricas, ainda que em processos determinísticos e ordenados, tendo em vista que se verificam em sistemas complexos. Nesse sentido, suas premissas mostram a dicotomia entre ordem e desordem nestes sistemas, pela dificuldade na observação completa do processo em virtude de sua natureza complexa. Como salienta Carvalho, a ordem é observada através das regularidades que, no entanto, podem ser poluídas por ruídos, ou pelas características erráticas, que caracterizam a desordem. Portanto "a meta otimista da ciência, qualquer ciência, é a descoberta da ordem por trás da desordem" (Carvalho, 1994, p. 179).

De modo diferenciado do que se verifica nas ciências naturais, como a estudada por Lorenz - em que a desordem do universo decorre de perturbações e características de processos complexos, que podem ser investigados e testados em laboratórios na busca de uma aproximação da realidade pela recombinação das partes isoladas -, nas ciências sociais, como na Economia, as perturbações podem ocorrer por interferência de ações humanas com propósitos diferenciados e as interações entre agentes resultam das tomadas de decisão em cada plano orientado para fins específicos, que se cruzam com mútuas influências.

Pesquisando sobre as incertezas que prescrevem a tomada de decisão empresarial ou de consumo nas últimas décadas, João Kon mostra que a turbulência advinda da aceleração das mudanças terá que ser enfrentada pelas ações humanas com flexibilidade, criatividade e prontidão, desde que 
[...] ficam cada vez mais claras as mudanças de paradigmas, a constante alteração de regras, a quantidade avassaladora de informações, a imprevisibilidade dos acontecimentos. Tudo nos leva a crer que a normalidade para os próximos anos será a de turbulência, incertezas e imprevisibilidade. (Kon, 1998, p. 6)

Entretanto, este autor não entende essa turbulência como algo negativo, mas sim como uma proposta dinâmica e positiva de aperfeiçoamento. Para fazer um paralelo com o comportamento humano, evoca as ideias de Ilya Prigogine que, baseado em experiências com Termodinâmica, conceitua o fenômeno que denominou de Estruturas Dissipativas como sendo sistemas vivos não lineares, afastados do equilíbrio, nos quais a instabilidade (Caos) leva a novas formas de comportamento e, consequentemente, novas ordens e estruturas, diferentes das anteriores (Prigogine e Stengers, 1991).

Prigogine e Stengers (1991) demonstram como estas turbulências são fatores centrais no desenvolvimento de novas formas complexas de organização. As estruturas dissipativas são compostas por uma variedade de subsistemas que interagem de forma não linear, tanto interna quanto externamente. Em continuidade, os autores demonstram que existe uma preferência dos sistemas que se encontram nestas condições, para selecionarem determinados caminhos, entre todos os possíveis, como decorrência do potencial de auto-organização, que cria uma nova forma mais avançada de estrutura, mais complexa e mais capaz de realizar trabalho e atividades do que a anterior.

Para provar a força intrínseca inerente à situação de desordem do caos que leva o sistema a se reorganizar em uma nova ordem, Kon (1998) recorre aos biólogos chilenos Francisco Varela e Humberto Maturana, que elaboraram a Teoria da Autopoiese, termo que se refere à autocriação, integração, auto-organização dos sistemas vivos impelidos pela sobrevivência, ou seja, à propriedade destes de serem intergerativos para garantirem a continuidade do sistema: um só existe a partir do outro, assim como o indivíduo e a sociedade.

Em 1971 Nicolas Georgescu-Roegen definiu em seus estudos a premissa de que as leis da entropia podem constituir as bases para a análise econômica, o que implica mudanças na visão econômica, particularmente da análise evolucionária, desde que a dinâmica dos sistemas econômicos vivos não lineares (enquanto estruturas dissipativas) deve ser vista como constituída de processos qualitativos constantes de mudança estrutural, ou seja, de auto-organização contínua. Este autor desenvolveu a ideia aplicada a sistemas econômicos de que o desenvolvimento da complexidade estrutural destes sistemas leva à desordem que libera energia, mensurada pelo grau de entropia.

Associado a estas ideias, o conceito de Entropia ajuda a entender as forças intrínsecas às situações de desordem ou caos, que geram a possibilidade de regeneração do sistema (autopoiese). A entropia é um conceito utilizado inicialmente em termodinâmica e transportado para explicar movimentos da Economia, que mede a desordem de um sistema, ou seja, as trocas interiores entre elementos que o com- 
põem. Através da medida representada pela entropia, é avaliada a degradação da energia de um sistema, ou seja, a energia liberada pelo sistema na situação de desordem significa a perda de recursos não aproveitados: quanto maior for a desordem de um sistema, maior será o grau de entropia. Na Economia, esta perda de energia diz respeito aos recursos humanos, financeiros e tecnológicos não utilizados em uma situação de desordem e instabilidade.

Para alguns teóricos da década de 1980 que aplicaram o conceito à Economia, a entropia mede a perda da quantidade de energia disponível para executar qualquer outro tipo de trabalho, e se refere particularmente à sustentabilidade ambiental (Villela e Cavalcanti, 1981). As abordagens mais recentes, no entanto, explicam que a entropia pode significar o aumento da ordem na desordem, desde que a energia não pode ser criada nem destruída, mas apenas transformada. Por meio do processo de transformação a energia flui através da cultura e do sistema humano, onde é utilizada para sustentar a vida em um estado de não equilíbrio (Araujo et al., 2015).

A visão da análise aqui desenvolvida é de que a energia liberada na desordem do sistema econômico representa a liberação de recursos humanos e tecnológicos que ficam ociosos e podem ser aproveitados na criação de uma nova ordem no sistema.

Mais recentemente, o matemático Marcelo Viana (2001) mostrou que os estudos de Lorenz permitem demonstrar e testar matematicamente o determinismo do caos, bem como a ideia de que existe uma ordem e um padrão nesse determinismo, pois existe uma equação que define o seu comportamento. A matemática introduziu ferramentas que permitem estudar e comprovar a existência destes fenômenos complexos não lineares através de métodos científicos. As condições destes processos caóticos podem ser perfeitamente quantificáveis e previsíveis pela utilização de modelos matemáticos ${ }^{1}$ analíticos ou numéricos que descrevem o sistema utilizando equações não lineares. Nesse sentido, o desenvolvimento da matemática do caos, baseada em modelos econométricos não lineares multivariados, busca a descrição da dinâmica de processos econômicos através e uma abordagem diferenciada dos modelos simplistas de equilíbrio que explica movimentos convergentes.

Nesse sentido, economistas estudiosos da Teoria do Caos buscam explicar a ordem na desordem, com a suposição de que existe uma estrutura por trás da desordem, que mostra que para dadas condições de partida os resultados obtidos são caóticos, porque imprevisíveis, mas não são arbitrários. Valem-se da expressão "limiar do caos" como uma metáfora utilizada para as ciências de modo geral, para representar o modo como alguns sistemas físicos, biológicos, econômicos e sociais oscilam entre a ordem e a desordem nas situações de caos. A este respeito, os estudos sobre sistemas sociais buscam investigar como e por que, nos períodos de crises,

\footnotetext{
${ }^{1}$ Foge dos objetivos deste trabalho a investigação matemática dos fenômenos econômicos explicados, o que tem sido extensivamente efetuado por estudiosos desta área como Olivo (2010) e Mauerberg Jr., (2013), entre outros.
} 
a ação humana lida com contextos permeados simultaneamente por ordens e constrangimentos, bem como caos e criatividade, visando à sobrevivência e à resistência à adversidade. Neste contexto, os agentes recorrem a improvisos e criatividade, como alternativas dinâmicas radicais.

Em suma, a Teoria do Caos aplicada ao entendimento das turbulências na Economia nos mostra uma nova normalidade, o fim das certezas, pequenas causas gerando grandes efeitos, mas a partir da ideia de autopoiese é observada a potencialidade dos sistemas caóticos de resgatarem endogenamente a força dinâmica ociosa liberada para construir uma nova ordem. As novas ordens geradas pelas turbulências e instabilidades podem ter a conotação de movimentos dinâmicos, positivos, possibilitando a convivência com a formidável aceleração das mudanças em curso.

\section{O CENÁRIO DE INCERTEZAS, AS EMPRESAS DE ALTA TECNOLOGIA E O SURGIMENTO DE STARTUPS}

Os antecedentes das transformações disruptivas no cenário econômico mundial começaram a se delinear com as primeiras firmas de comunicação através da Internet, fundadas por capitais de risco nos anos 1980 no Vale do Silício (EUA), quando foram criadas as primeiras startups, que até 1994 tiveram lenta evolução, quando começaram a financiar planos de empreendedores para a exploração comercial da Internet. Algumas empresas de pequeno porte se formaram no Vale e passaram a desenvolver softwares para assessorar e instrumentar o uso da Internet pelas maiores empresas, utilizando financiamento próprio, além do capital de risco (Kenney, 2004).

O cenário econômico mundial de incertezas teve um crescimento acelerado nos anos 1995 a 2001, quando a tecnologia da comunicação via Internet al.cançou um aquecimento considerável resultando na denominada "Bolha da Internet". Neste período, a Internet veio ocupando cada vez mais espaço na produção, na comunicação mundial e no cotidiano dos indivíduos, alterando consequentemente alguns cenários. Nos países industrializados, as empresas baseadas na Internet foram consideradas setores altamente promissores, sem limite de lucros e passaram a concentrar a maior parte dos investimentos, embora sem previsão exata de retornos em longo prazo. O setor de tecnologia passou a ser avaliado como detentor de elevado potencial de valorização, pois a imagem a respeito do e-commerce era de que no futuro estas empresas iriam conquistar lucros extraordinários e incalculáveis. Como consequência, várias empresas abriram capital na bolsa de valores, cujas ações tiveram valorizações acima dos parâmetros fundamentais, por conta da euforia e especulação. Este excesso de confiança pode justificar o uso de estratégias empresariais que não seriam compensatórias em um ambiente racional (Kenney, 2004).

A bolha se caracterizou como um fenômeno relacionado a prejuízos para o mundo tecnológico, porém, foi muito importante para que a Internet ganhasse grandes proporções nos anos seguintes de forma mais sólida. Durante este período, os 
países passaram por grandes transformações na economia, no meio ambiente, nos sistemas societal e político. As crescentes oportunidades de desenvolvimento implicaram também aumento nos riscos sistemáticos que envolveram todo o sistema de interconexões regionais e mundiais. Neste período, observou-se o aparecimento de alto desemprego estrutural e de subemprego, resultantes da instabilidade e incertezas quanto às formas de lidar com os riscos; estes riscos por sua vez se apresentavam interconectados com impactos sistêmicos, tanto entre setores de uma economia quanto em nível internacional, tendo em vista o processo de globalização.

Sucederam-se crises econômicas em várias regiões mundiais, como as crises dos Gigantes Asiáticos (1997), do rublo no sistema bancário da Rússia (1998), das “pontocom" (2000), dos atentados às Torres Gêmeas dos EUA (2001), a argentina (2001-2002), a crise financeira e recessão mundial (2008-2009), a da dívida na Europa originada na Grécia (2009-2010). Este cenário mundial de incertezas configurou a complexidade e a desordem nos sistemas econômicos, políticos e sociais mundiais, ou seja, sistemas econômicos caóticos e instáveis com impactos imprevisíveis das tomadas de decisão dos agentes envolvidos; este cenário, embora tenha se atenuado, manteve continuidade até a atualidade.

Os efeitos das seguidas crises financeiras mundiais sobre os sistemas bancários e financeiros resultaram em crescente complexidade nos sistemas econômicos em virtude da interação entre as regras próprias seguidas pelos vários agentes econômicos mundiais, com a consequente desordem resultante, em decorrência das condições iniciais diferenciadas de cada contexto socioeconômico, nos moldes das conclusões de Lorenz. A subsequente restrição de crédito financeiro para os setores produtivos decorreu do aumento do risco e da impossibilidade de previsão sobre os retornos das atividades produtivas, o que repercutiu de modo relevante no crescimento do custo de consumo dos produtos tangíveis e intangíveis.

A desordem resultante acarretou aumento de mercados não atendidos e em crescente incerteza quanto à validade da aplicação do capital financeiro disponível para o atendimento destes mercados através dos padrões de operacionalização vigentes. Em países populosos e que dispunham de desenvolvimento tecnológico progressivo, os objetivos de inovar se voltaram para a criação de novos modelos e processos que conduzissem ao atendimento das deficiências do mercado e à aplicação mais rentável do capital financeiro na produção. Assim, a ideia schumpeteriana de soluções disruptivas para a transformação de processos e modelos produtivos ganhou espaço através do crescimento de grupos de agentes empreendedores que, visando à sobrevivência no ambiente de incertezas e turbulência, passaram a trabalhar com ideias diferenciadas para a estruturação de sua produção, utilizando em grande proporção tecnologia digital avançada (Bower e Christensen, 1995).

Para competir os agentes produtivos precisam achar o "limiar do caos", ou seja, o ponto onde há tanto ênfase na competição e adaptação do modelo existente quanto na criação e desenvolvimento de novos modelos. A ideia subjacente é de que estes agentes precisam investir em alternativas diversas, desde que a diversidade de estratégias é o insumo básico da inovação e do processo adaptativo à nova 
realidade, para competir desenvolvendo novas formas de vantagens. Assim, as condições de complexidade econômica levaram diretamente a uma mudança de paradigma e estas perspectivas afetaram a gestão de sistemas organizacionais produtivos (Borgatti Neto, 2002).

A mudança de estratégia e de paradigmas de negócios caracterizou a evolução acelerada das startups, sinônimo de empresas iniciantes, que dos Estados Unidos propagou-se para outros países industrializados e em grande escala para a China, Índia e Israel. No entanto, ressalte-se que nem todo novo empreendimento resulta em startups, desde que a ideia inovadora busca um modelo de negócios repetitível e escalável, com potencial de atingir um grande número de consumidores com rápida geração de lucros, com base tecnológica avançada (aplicativos) utilizada em novos modelos de atendimento de serviços. Caracterizam-se por aspectos específicos, definidos como autonomia dos agentes para assumir a responsabilidade e a rapidez de decisões, competitividade, independência na definição dos objetivos, disposição para risco e dedicação, por meio da criação de um modelo de negócios inovador ou adaptado para uma nova aplicação no mercado e em constante renovação (EC, 2018).

Em geral, nas economias em que se desenvolvem, as startups dão origem a uma série de instituições de apoio, particularmente compostos por duas formas de funcionamento: (i) incubadoras, que proporcionam o suporte para a criação e desenvolvimento de ideias, para a elaboração dos recursos administrativos, de infraestrutura e tecnológico do novo produto; e (i) aceleradoras, que oferecem recursos financeiros, mentoria, networking de apoio à operacionalização da empresa, entre outros.

$\mathrm{O}$ atendimento dos clientes se dirige para múltiplos formatos de relacionamentos, entre: (i) empresas (B2B ou business-to-business); (ii) empresas e consumidores (B2C ou business-to-consumer); e (iii) empresas para empresas e para consumidores (B2B2C ou business-to-business-to-consumers), via triangulação; (iv) entre empresas e empregados (B2E ou business-to-employee); (v) empresas e governo (B2G ou business-to-government); consumidor e consumidor (C2C ou consumer-to-consumer);(vi) de investimentos entre consumidores sem mediação de bancos (P2P ou peer-to-peer); e (vii) entre empresa e diversos fornecedores em um mercado livre (marketplace) (Mafra, 2018). Estas várias modalidades de relacionamentos surgiram para atender deficiências de convivência entre agentes e entre mercados, através da criação dos novos modelos e se caracterizam pela criação de uma identidade baseada na diferenciação do processo produtivo, do produto ou dos serviços, em relação às modalidades tradicionais.

Entre as vantagens do investimento em startups, destaca-se o retorno financeiro devido ao crescimento quase ilimitado da escala, muitas vezes sem a necessidade de expandir a estrutura, desde que o grupo de trabalho pode ser pequeno e multifuncional, com alta flexibilidade de funções, onde os ganhos elevados são proporcionais ao alto risco. Ao lado disso, a velocidade de consecução de retornos financeiros acima da média pode ser maior do que em modelos tradicionais, tendo em 
vista menor burocracia e a criação de uma nova modalidade de atividade econômica que gera demanda adicional (Kerényi et al., 2018).

Como salientam Joseph L. Bower e Clayton M. Christiansen (1995), esta disrupção se dá como um processo através do qual uma nova empresa com poucos recursos é capaz de desafiar com sucesso empresas já estabelecidas no mercado que não têm interesse em atender às necessidades de alguns segmentos de consumidores menos lucrativos. Por outro lado, diversas formas alternativas de obtenção de capital para o investimento agilizam sua criação e facilitam a rápida evolução do empreendimento, seja por meio de participação direta do capital do empreendedor, de empréstimos de investidores-anjos (aportes de capital de terceiros não sócios, pessoa física ou jurídica ou fundos de investimento), de empréstimo conversível em participação, de títulos de emissão da sociedade anônima (debêntures e bônus de subscrição) ou ainda de investimentos por plataformas de financiamento coletivo (crowdfunding) (EC, 2018).

Assim, particularmente desde a crise financeira mundial de 2008, acelerou-se a necessidade de mudanças nos modelos operacionais do processo de produção e distribuição de determinadas atividades tangíveis e intangíveis, devido a questões de gerenciamento das normas legais e regulamentares (compliance) e das políticas de ação expressas pelas novas diretrizes estabelecidas para lidar com a situação de instabilidade. Esta revolução digital das últimas décadas possibilitou que múltiplos centros de startups florescessem e chegassem à maturidade nos últimos 10 anos no mundo. Nos países avançados, particularmente nos países de ambientes mais propícios para o desenvolvimento da inovação, empresas digitais nascentes passaram a requerer uma variedade de agentes e processos de apoio, que são chamados de ecossistemas de startups de softwares (software startup ecosystem), essenciais para a inserção dos países na economia digital. No entanto, é muito difícil de serem encontrados em todos os países estes elementos que compõem o ambiente necessário para a evolução deste ecossistema de inovação (Cukier e Kon, 2018).

Daniel Cukier e Fabio Kon (2018) desenvolveram um modelo para determinar a maturidade de ecossistemas de startups, visando entender sua evolução e dinâmica, os elementos que influenciam seu comportamento e como se relacionam com outros agentes do ecossistema. Comparam três ecossistemas (Tel Aviv, Nova York e São Paulo) que funcionam em três realidades socioeconômicas completamente diferentes, constatando que estes não podem ser analisados como entidades estáticas, pois estão em constante transformação no tempo e, como outros organismos vivos, algumas mudanças são planejadas ou controladas de certa maneira, enquanto outras resultam de forças não esperadas, endógenas ou exógenas ao sistema.

Os resultados mostram que apesar dos diferentes ambientes, os três ecossistemas analisados passam pelos mesmos estágios de evolução, embora apresentem situações econômicas estruturais e conjunturais muito diversas, são compostos pelos mesmos tipos de agentes (empreendedores, sociedade, governo, universidades, organismos de financiamento) e as interdependências e relacionamentos entre estes agentes ocorrem de maneira similar.

Literatura recente sobre o tema (Westlund et al., 2011) mostra a alta correla- 
ção positiva entre empreendedorismo (medido como número de startups) e crescimento econômico. Investiga a influência de normas, valores, redes e outros ativos localizados sobre a evolução destas novas modalidades de empreendimento. Encontram evidências de que o denominado Capital Social Empresarial local (Local Entrepreneurial Social Capital) se correlaciona com a frequência de startups em municipalidades economicamente avançadas. Isto se dá tendo em vista que os impactos destas empresas não são limitados a efeitos em seu próprio mercado, mas também aos efeitos no contexto econômico mais amplo de outras firmas.

No entanto, em face dos elevados riscos, a criação de startups se reveste de grande chance de insucesso, a partir do caráter e do perfil do empreendedor e dos demais funcionários, que devem apresentar características específicas, o que leva a maior instabilidade neste tipo de emprego do que em outras modalidades de empresas. Desvantagens adicionais são advindas das constantes mudanças na estratégia e no posicionamento no mercado, que costumam passar continuadamente por reformulações, sobretudo em seus primeiros anos, particularmente porque ainda são desconhecidas do mercado. Tendo em vista as limitações ao contar frequentemente em seu início com poucos recursos financeiros, tecnológicos ou humanos, a cobrança por resultados é grande, principalmente por parte dos investidores (KERÉNYI et al.., 2018).

\section{AS STARTUPS BRASILEIRAS: NOVA ORDEM EM UM CENÁRIO DE TURBULÊNCIAS}

\section{O cenário de instabilidade econômica e a liberação de recursos ociosos}

O cenário mundial de crises apresentado anteriormente resultou em impactos negativos no desempenho da economia brasileira; no entanto, as deficiências estruturais macro e microeconômicas do país já existentes ampliaram a conjuntura de perda de dinamismo que configurou em estagnação desde 2014. A indústria, que desde o início dos anos 2000 vinha perdendo dinamismo, observou um desempenho que veio se agravando até a situação de desindustrialização a partir de 2010 (Santos, 2019), acompanhada pela estagnação dos serviços e pela diminuição das exportações, fatores que contribuíram para o desestímulo aos investimentos. $\mathrm{O}$ agravamento do desemprego em altos níveis, compondo um mercado de trabalho deteriorado com uma subutilização da força de trabalho em torno de $25 \%$ no primeiro trimestre de 2019 e um mercado formal restrito a $36 \%$ da população ocupada, segundo os dados do IBGE (IBGE, 2019), repercutiu no consumo e na renda média dos brasileiros. A economia brasileira completou a primeira metade de 2019 com um quadro de paralisia em amplos setores da economia. As interferências e acasos (embates políticos exacerbados e combate à corrupção) no decorrer deste período crítico brasileiro, associados a outros fatores econômicos que representavam barreiras a novos investimentos (crescimento da dívida pública, elevado desequilíbrio fiscal), aprofundaram o panorama de instabilidade, incerteza 
e desordem recorrentes que caracterizam os sistemas complexos caóticos, que apontam para instabilidade em longo prazo.

Além do mais, o elevado "custo Brasil" no período - que encarece os produtos exportados em cerca de $30 \%$ em relação aos preços internacionais - não apenas desestimulou os investimentos e a produção brasileira, como também afetou diretamente a capacidade de poupança interna e de geração de divisas via exportação ao dificultar a participação do país nas cadeias produtivas mundiais. Este custo é representado, entre outros, por fatores como taxa de câmbio inadequada às exportações, altos juros bancários, carga tributária elevada e mal distribuída. Ao lado disso, a insuficiência de infraestrutura logística encarece os custos portuários, aeroportuários e das demais modalidades de transporte, que se associam à inadequada regulação governamental, à gestão pública deficiente, exageradamente burocrática, ineficiente e ineficaz, o que tornam os custos de transação das empresas extremamente elevados, afetando a tomada de decisão dos agentes (Kon, 2016a).

Dessa forma, o cenário de incertezas, imprevisibilidade e desordem se difundiu por vários setores como, entre outros, o financeiro, transportes, saúde e ensinos, cujos mercados se ressentiram da falta de eficiência no atendimento de suas demandas através dos sistemas tradicionais. O consequente elevado grau de entropia que representou a liberação de recursos ociosos - que no contexto econômico do Brasil se definiu claramente a partir de 2014 - criou as motivações que levaram à difusão acelerada da criação de startups no país, que ocuparam espaço na assistência das necessidades não atendidas, com maior rentabilidade que as organizações costumeiras. Estas startups surgiram para solucionar os problemas da demanda, seja ao criar novos serviços ou otimizar serviços existentes, para atender clientes insatisfeitos com o status quo do atendimento usual.

Assim, o Brasil desde 2014 teve oportunidade e necessidade de utilização destes recursos liberados pela estagnação econômica, na aplicação no desenvolvimento acelerado de startups. Estes recursos foram representados principalmente pela ociosidade de dois fatores essenciais ligados ao conhecimento: (i) profissionais de alta qualificação, que se encontravam em situação de desemprego, subemprego ou desalento e (ii) conhecimento tecnológico disponível, que se associaram a recursos financeiros ociosos devido à incerteza, em busca de inversão rentável.

No contexto da desordem econômica do período, este contingente de profissionais atingiu níveis inusitados. O número de brasileiros que procuram trabalho há pelo menos dois anos chegou a 3,3 milhões no primeiro trimestre de 2019, o que significa um aumento de $42,3 \%$ desde 2015 . Embora esta situação no país afete mais os trabalhadores menos escolarizados e as famílias de menor renda, segundo o IPEA (2019), a taxa de desemprego do período atingiu também consideravelmente a mão de obra qualificada no país que buscou sobrevivência por meio do empreendedorismo via startups. No âmbito da estruturação ocupacional brasileira, esta mão de obra mais qualificada, composta por dirigentes de empresas, profissionais liberais que trabalham por conta própria e outros qualificados, tem mantido recentemente uma representatividade em torno de $18 \%$ da força de trabalho (Kon, 2016b). 


\section{A disponibilidade de infraestrutura e da institucionalização do apoio governamental}

A evolução das startups se difundiu, apesar de as políticas públicas para a criação de infraestrutura e regulação satisfatórias para o desenvolvimento do empreendedorismo no país ainda deixasse a desejar, em relação às condições adequadas para estímulo de novas empresas, como se observa pela Tabela 1, que apresenta os resultados do relatório de pesquisa Global Entrepreneurship Monitor (GEM) para 2018-2019.

Tabela 1: Classificação internacional sobre a disponibilidade de infraestrutura para o empreendedorismo - Brasil, 2018

\begin{tabular}{lcc}
\hline Fatores favoráveis ao empreendimento & Classificação & NECl- Brasil \\
\hline Finanças empresariais & 17 & 4,80 \\
Apoio e relevância das políticas governamentais & 50 & 2,77 \\
Políticas governamentais: tributos e burocracia & 54 & 2,03 \\
Programas governamentais de empreendedorismo & 45 & 3,34 \\
Educação escolar em empreendedorismo & 50 & 2,22 \\
Educação no estágio pós-escolar em empreendedorismo & 40 & 4,07 \\
Transferência de P\&D & 35 & 3,4 \\
Infraestrutura comercial e legal & 36 & 4,52 \\
Encargos e regulação do mercado interno p/ entrada & 44 & 3,65 \\
Infraestrutura física & 46 & 5,42 \\
Normas culturais e sociais & 51 & 3,38 \\
\hline NECl - total & 48 & 4,1 \\
\hline
\end{tabular}

Fonte: GEM (2019). Elaboração própria. $\mathrm{NECl}=$ Índice de condições de infraestrutura.

Escala do $\mathrm{NECl}: 1$ = posição insuficiente, muito inadequada; 9 = posição suficiente muito adequada.

Este relatório anual pesquisa em 54 países a disponibilidade de infraestrutura pública adequada para o desenvolvimento do empreendedorismo, classificando-os segundo um índice (NECI) que reúne uma série de variáveis específicas que representam os fatores motivadores para o empreendimento.

A tabela mostra que o Brasil, em comparação com os demais países selecionados que dispõem de um desenvolvimento considerável de startups em 2018, se classifica em uma posição desvantajosa, situando-se no contexto global do indicador NECI em $48^{\circ}$ lugar entre os 54 . Entre os aspectos favoráveis apenas a infraestrutura para financiamento empresarial $\left(17^{\circ}\right)$ se coloca em melhor posição relativa. Da mesma forma, os resultados do índice NECI apresentam a mesma situação, desde que, com exceção destes dois indicadores, os demais se encontram abaixo da metade inferior da escala do indicador.

Por outro lado, o ambiente para a competitividade digital do Brasil no contexto mundial também não era satisfatório no período (Figura 1), como pode ser observado através do estudo do Centro de Pesquisas sobre Competitividade da 
Business School de Lausane, responsável pela mensuração dos índices de competitividade digital mundial publicados no World Digital Competitiveness Ranking - IMD 2017.

Figura 1: Posição do Brasil na classificação mundial de competitividade digital segundo os subfatores de Tecnologia - 2017

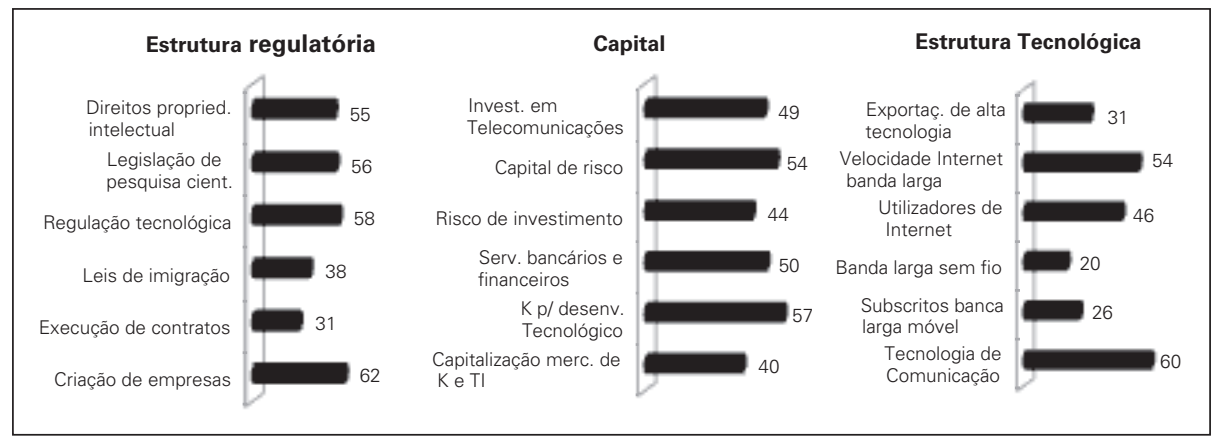

Fonte: IMD (2017). Elaboração própria.

A Figura 1 mostra a classificação internacional do Brasil, entre 63 países pesquisados, para alguns fatores-chave determinantes do ambiente favorável à competitividade digital, tanto de empresas privadas como na esfera estatal e que moldam a competitividade digital do país. Observe-se que no período analisado a maior parte dos fatores relacionados à estrutura regulatória, à disponibilidade de capital e à estrutura tecnológica do país encontram-se classificados nas posições inferiores do ranking, com exceção da disponibilidade de algumas tecnologias de banda larga sem fio e móvel.

Embora parte considerável das startups que já se consolidaram apresente tendências de evolução com vistas a mercados internacionais e com interesse na participação em ecossistemas de inovação, o ambiente regulatório e legal no país ainda não está completamente desenvolvido e existe enorme insegurança jurídica a respeito, em grande parte devido à concentração da atenção econômica global para a solução prioritária de desequilíbrios macroeconômicos e para efetivação das reformas políticas e jurídicas urgentes, o que paralisou as ações de aperfeiçoamento do ambiente favorável.

No que se refere ao papel do governo na preparação do ambiente institucional mais propício, observa-se que as medidas ainda são tímidas. O Ministério da Ciência, Tecnologia e Inovação (MCTI) lançou, em 2012, o Programa Estratégico de Software e Serviços de Tecnologia da Informação (TI Maior), que visa ações de incentivo, fomento e financiamento à pesquisa e desenvolvimento em TI. O TI Maior foi estruturado em cinco bases: desenvolvimento econômico e social; posicionamento internacional, inovação e empreendedorismo; produção científica, tecnológica; e inovação e competitividade. No entanto, este e os demais programas foram centrados especificamente no desenvolvimento de softwares e de outras TI, não atendendo à amplitude das necessidades diferenciadas das startups. 
Outras iniciativas governamentais podem ser citadas, porém carecem de maior detalhamento e medidas efetivas de implementação, como: (i) Programa Startup Brasil (2013), que tinha como meta acelerar 150 startups de softwares e serviços de TI até 2014, sendo $25 \%$ de startups internacionais localizados no Brasil. Visava à aproximação entre startups, instituições de ciência e tecnologia com grandes empresas, por meio de parcerias das aceleradoras, para apoiar as empresas germinadoras de base tecnológica; (ii) Projeto de Lei $n^{\circ}$ 321/2012, não homologado, que concede isenção dos impostos federais para novas empresas de tecnologia (startups); (iii) Lei Complementar 155/2016, que regula os incentivos para investimentos em startups, também não homologada; (iv) Programa InovAtiva Brasil, lançado pelo governo em 2013, um dos premiados pela 19a edição do Concurso Inovação em Gestão Pública Federal da Escola Nacional de Administração Pública, é voltado para a capacitação e a mentoria em larga escala para startups, como negócios inovadores em desenvolvimento ou nos seus primeiros anos de vida; (v) Concurso INOVApps, lançado em 2014 pelo Ministério das Comunicações com o objetivo de apoiar o desenvolvimento de aplicativos e jogos sérios de interesse público para dispositivos móveis e TVs digitais conectadas (Abfintechs, 2018; Roncaratti, 2017).

\section{O panorama atual das startups no Brasil}

O panorama atual das startups no país, aqui examinadas até 2019, se desenvolveu em um ambiente consideravelmente burocrático, com estrutura logística insuficiente, além de altas taxas de juros e impostos exorbitantes. A ABStartups estima que existiam mais de 62 mil empreendedores e 13.299 startups em 2019, número que mais que quintuplicou desde 2012 (2.519 cadastradas), registrado quando o país ainda começava a discutir o modelo e a perceber o nascimento do novo mercado. Segundo a Associação, muitas ainda estão na fase de ideias e nem todas têm o Cadastro Nacional da Pessoa Jurídica (CNPJ). No mesmo período a evolução anual do PIB brasileiro foi de $0,1 \%$.

Assim, o crescimento anual do número destas empresas tem se situado em quase $20 \%$, não obstante a crise enfrentada pelo país e, portanto, existe uma alta taxa de abertura de empresas, apesar dos grandes riscos percebidos. Em 2018 o Brasil teve seus primeiros unicórnios, assim denominadas empresas que atingem o valor de mercado de US\$ 1 bilhão: 99, PagSeguro, Nubank, Stone e iFood, o que despertou a atenção de investidores e grandes empresas (ABStartups, 2019).

Estas empresas digitais se difundiram por uma grande variedade de mercados, como apresentado no Gráfico 1, que apresenta as representatividades das $50 \%$ maiores (as demais têm individualmente participação abaixo de $1 \%$ do mercado), observando-se em 2019 as maiores concentrações na área de Educação (a mais representativa), Finanças e Saúde e Bem-Estar. 


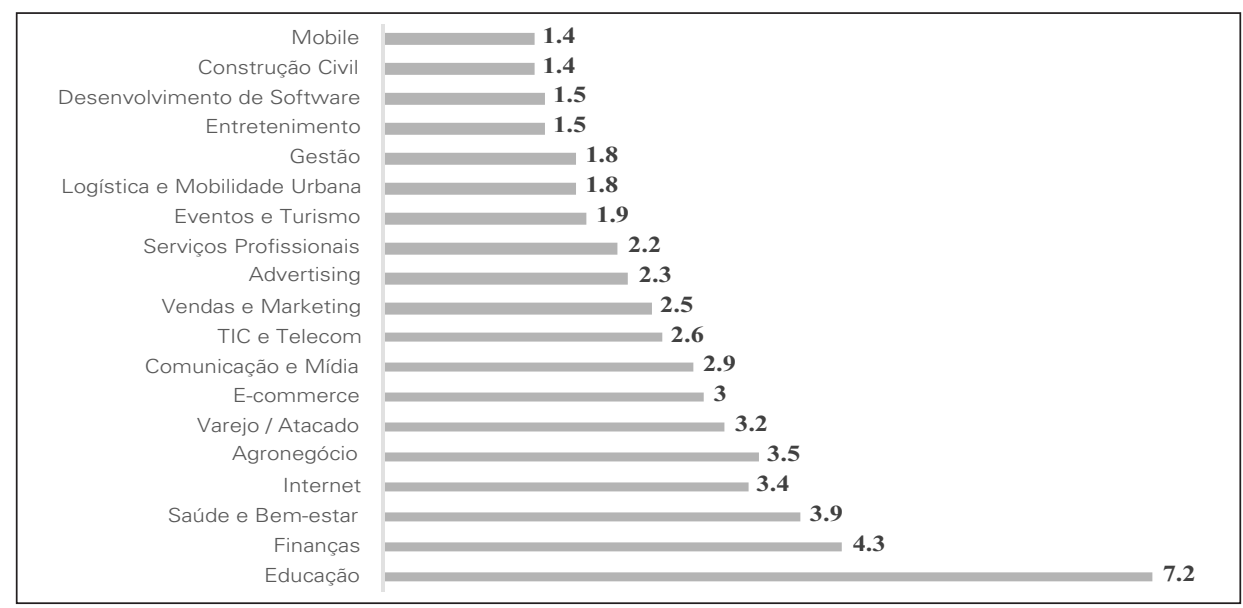

Fonte: ABStartup (2020). Elaboração própria.

A pesquisa de Cukier e Kon (2018) mostra que entre os requisitos mínimos para que uma startup exista está a disponibilidade de empreendedores qualificados mesmo no primeiro estágio nascente de um ecossistema. Neste sentido, quanto à qualificação dos empreendedores no país em 2017, 42\% dos empreendedores de startups financeiras possuíam nível de escolaridade de pós-graduação, 14\% com mestrado, $2 \%$ com doutorado e $39 \%$ tinham concluído a graduação, cujas principais áreas de formação são Administração (31\%), Tecnologia da Informação (27\%), Engenharia (11\%) e Marketing (10\%). Apenas 11\% destes novos empreendedores não haviam atuado anteriormente no setor corporativo, onde $49 \%$ atuaram em outro segmento e $40 \%$ no mesmo ramo (ABFintechs, 2018). Isso reforça a ideia de que a criação destas novas empresas foi em parte impulsionada pela disponibilidade de profissionais qualificados que se encontravam sem trabalho.

Perfil semelhante de qualificação ocorreu nos demais segmentos de atividades em que se localizaram os novos paradigmas com plataformas digitais como base de operacionalização, observando-se que os segmentos que mais concentraram estas empresas em 2017 foram os que forneciam serviços profissionais a outras empresas e a consumidores (16,3\%), serviços de Tecnologia da Informação e Telecomunicações $(11,0 \%)$, serviços Financeiros $(8,8 \%)$ e Saúde $(8,2 \%)$. No entanto, em julho de 2019 a ABStartups relata que o setor de startups tinha a disponibilidade de cerca de 5 mil vagas, mas sem encontrar funcionários com suficiente capacitação para assumi-las, tendo em vista o requisito de especialização nas tecnologias avançadas.

Com relação às fontes de investimento, quase $77 \%$ tem origem nas reservas pessoais dos sócios, desde que no período de estagnação a mão de obra qualificada, que tinha poucas opções de permanecer empregada e um volume suficiente de 
poupança, encontrou uma combinação de boas oportunidades de atender à demanda a partir destes novos empreendimentos. Estes empreendedores encontraram uma forma de recriar (autopoiese) suas oportunidades de trabalho no cenário de incertezas, em que outras formas de investimento não estavam disponíveis. Outra forma criativa de atender a necessidades de financiamento é representada por investidores-anjos, que participam em média um pouco acima de $9 \%$ das empresas, além do aumento considerável de empresas voltadas para aquisição de recursos via crowdfunding, ou seja, financiamento coletivo através da agregação de múltiplas fontes de financiamento, em grande parte constituídas por pessoas físicas. Além destas fontes de investimentos, as demais que englobam $6,6 \%$ das empresas são originadas principalmente de financiamento bancário e reinvestimentos internos.

Gráfico 2: Distribuição das startups

brasileiras segundo público-alvo (\%)

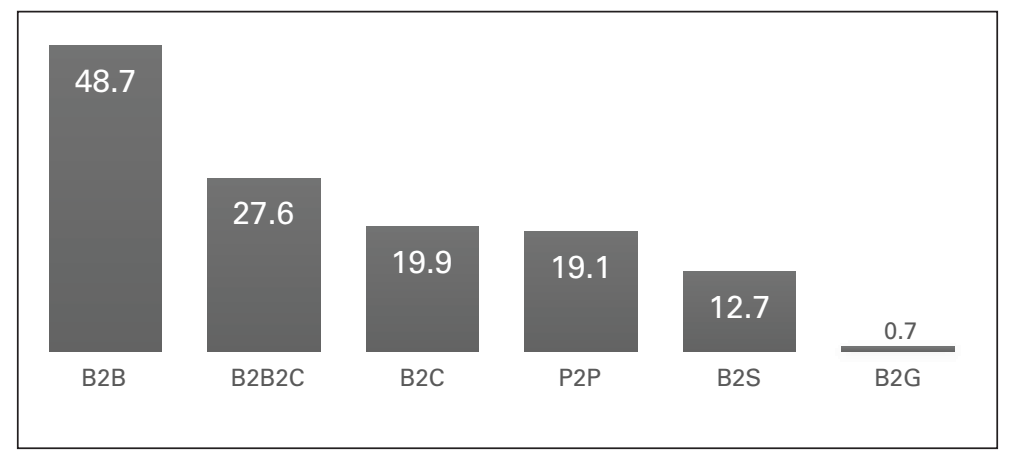

Fonte: ABStartup (2020). Elaboração própria.

Segundo a ABStartups, na atualidade o perfil dos clientes é consideravelmente concentrado no relacionamento entre empresas (B2B) que, incluindo outras startups (B2S), agrega quase $52 \%$ dos demandantes e, se inclui a triangulação com consumidores privados (B2B2C) chegam a quase $80 \%$. Outras formas de atendimento a consumidores individuais são compostas em $19,9 \%$ por relacionamentos diretos entre empresas e consumidores finais (B2C) e 19,1\% por empréstimos entre consumidores sem mediação de bancos (P2P). O governo (B2G) apenas muito recentemente está utilizando serviços destas empresas digitais, desde que tem uma representatividade menor que 1\% (Gráfico 2).

As empresas clientes relatam as vantagens que os novos modelos de startups trazem ao atendimento de suas demandas: quase $21 \%$ nomeiam a melhora nos produtos e serviços como resultado da inovação, $20 \%$ a simplificação dos processos, $18 \%$ a redução de custos, $16,5 \%$ aumento de produtividade, $8 \%$ economia de tempo e $7,2 \%$ alcance de novos mercados, entre outras. 


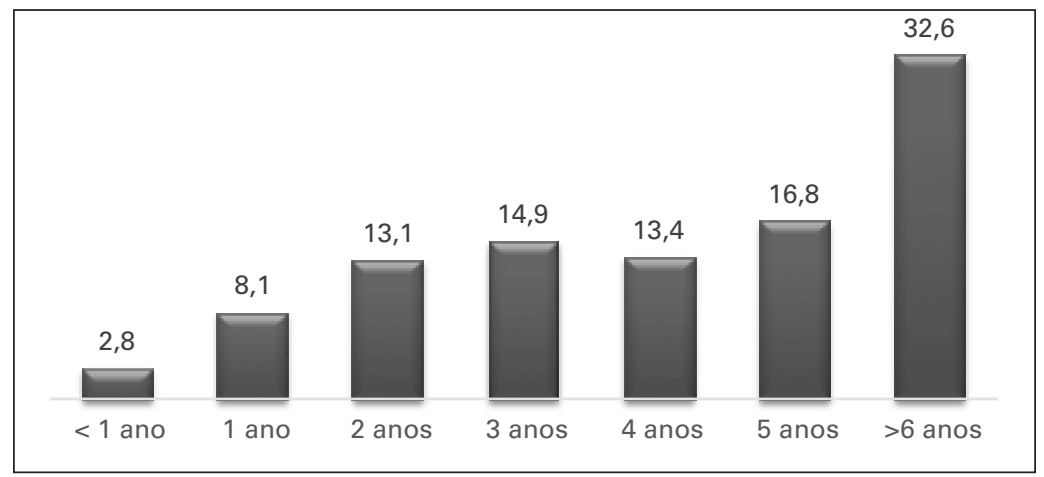

Fonte: ABStartup (2020). Elaboração própria.

O exame do perfil das empresas na atualidade mostra que as startups brasileiras são jovens (Gráfico 3) e de pequeno porte, encontrando-se em fase de amadurecimento, desde que apenas $1 / 3$ tem mais de 6 anos de idade e $63 \%$ tem menos de seis membros. Por outro lado, $39 \%$ ainda não apresentam receita porque se encontram em estágios de projeto ou de início de operação, quando projetam as estratégias iniciais, os objetivos a serem perseguidos e os próximos passos para o amadurecimento. Do total de empresas, 69\% têm receitas anuais menores que $\mathrm{R} \$$ 50 mil e ainda não atingiram o estágio de tração, em que a empresa já ocupou um lugar no mercado e está amadurecida para a continuidade de operacionalização automática.

Pesquisa da ABStartups (2018) revela que os empreendedores salientam desafios encontrados que levam ao fracasso: insuficiência de recursos humanos qualificados (relatada por $50 \%$ dos casos); o alcance da escala para operações $(42 \%)$; obter recursos para investimentos $(29 \%)$; atender aos requisitos regulatórios $(25 \%)$, entre outros. Pesquisas internacionais revelam que o Brasil é considerado um mercado muito promissor para o desenvolvimento de startups que, no entanto, não se efetiva tendo em vista a insuficiência de mão de obra qualificada, dificuldades do ambiente regulatório, deficiência de infraestrutura de apoio logístico, além da insuficiência de capital.

No entanto, a colaboração entre empresas, aceleradoras e incubadoras para validar estes novos modelos de negócios, para ter acesso a know-how e buscar investimentos ainda é incipiente e cabe agilizar a implementação das medidas governamentais de apoio mais efetivas e dirigidas às características específicas de funcionamento das startups, bem como de divulgação destes benefícios, para atrair novos empreendedores. Nesse sentido, a natureza dinâmica destas empresas apresenta também desafios visando à agilidade das medidas de regulação e outras políticas governamentais, no momento de estagnação e incerteza em que se encontra o país. 


\section{CONCLUSÃO E CONSIDERAÇÕES FINAIS}

A criação e a evolução de empresas digitais startups no Brasil apresentaram desde 2014 taxas de crescimento aceleradas e constantes, apesar do cenário econômico de estagnação, instabilidade e turbulência em que os setores produtivos apresentaram crescimento nulo ou negativo. Neste contexto, a infraestrutura governamental de apoio para o desenvolvimento destas empresas mostra a insuficiência de instrumentos de regulação, financeiros e de inovação tecnológica, o que causa uma situação de competitividade internacional relativamente baixa no contexto internacional.

Observou-se que a evolução acelerada das startups no Brasil no período foi possível tendo em vista a utilização de recursos ociosos para a criação destas empresas, utilizando a tecnologia digital avançada disponível de forma inovada, com menores custos e maior eficiência. Estas empresas estabeleceram uma nova ordem nas formas de comportamento então vigentes, novos padrões de interação, bem como novas estruturas de organização, diferentes das anteriores.

A força intrínseca inerente à situação de desordem do sistema econômico brasileiro no período analisado levou alguns agentes econômicos privados à busca de reorganização ou regeneração de formas de oferta de serviços criativos, flexíveis e versáteis, para enfrentar as turbulências representadas pela carência do atendimento a parte da demanda. Isto se verificou tendo em vista que estas empresas atuam em lacunas deixadas pela economia em crise, preenchendo falhas na mobilidade urbana, na baixa oferta de crédito e nos custos elevados dos serviços principalmente os financeiros (fintechs), da saúde, ensino, alimentação e agronegócio (agtechs).

As startups brasileiras assim vêm cumprindo com a função de continuamente revitalizar o mercado não suprido por organizações que trabalham com formas mais tradicionais de operacionalização, em ambiência dinâmica e não linear e, dessa forma, difundem seus impactos positivos para outras empresas, possibilitando a modernização dos relacionamentos entre agentes da economia, sejam empresas, governo ou consumidores individuais e coletivos.

O mercado para estas empresas no Brasil constitui uma força considerável e apresenta um potencial muito grande de consumidores para a alavancagem da geração de valor adicionado e geração de renda. No entanto, as dificuldades relacionadas à falta de efetivação das políticas públicas causam obstáculos à continuidade das empresas e é observado no país um grau muito elevado de fechamento de startups.

\section{REFERÊNCIAS BIBLIOGRÁFICAS}

ABFintechs/PwC (2018). Pesquisa Fintech Deep Drive 2018. São Paulo: ABFintechs.

ABStartup, (2018, 2019 e 2020). Startupbase/Estatísticas. São Paulo: Abstartups. https://startupbase. com.br/stats

ARAUJO, U. P. SANCHES Jr., P. F. e GOMES, A. F. (2015). “Desafiando a interdisciplinaridade na ciência administrativa: o caso da entropia”. Cadernos FGV EBAPE.BR, v.13, no 4, Artigo1.

ARTHUR, W. Brian (2014). Complexity and the Economy, Oxford: Oxford University Press.

BORGATTI NETO, R. (2008). Perspectivas da Complexidade aplicada à gestão de empresas. São Paulo: Escola Politécnica/USP. 
CARVALHO, F. J. C. (1994). “Sobre ordem, incerteza e caos em Economia”, em Revista Brasileira de Economia, 48 (2).

CUKIER, Daniel e KON, Fabio (2018). “A maturity model for software startup ecosystems”. Journal of Innovation and Entrepreneurship, dezembro 2018

DAVIDSON, P. (1995). “Uncertainty in economics”. In: DOW, S.; HILLARD. J. (Eds.) Keynes, knowledge and uncertainty. Aldershot: E. Elgar.

EC (2018). European Union Startup Monitor-2018 Report. Brussels: European Commission.

GEM (2019). Global Entrepreneurship Monitor 2018/2019, Global Report. London: London Business School.

GEORGESCU-ROEGEN, N. (1986). "The Entropy Law and the Economic Process in Retrospect”. In: Eastern Economic Journal, Volume XII, No. 1.

IBGE (2019). PNAD Contínua - Comentários sintéticos, Brasil, Primeiro trimestre/2019. https://ww2.ibge. gov.br/home/pnad.

IMD (2017). IMD World Competitiveness Rankings 2017. Lausanne: IMD World Competitiveness Center. IPEA (2019). Carta de Conjuntura, junho 2019. Brasília: IPEA.

KENNEY, M. (2004). "What goes up must come down: The Political Economy of the US Internet Industry." In Jens Frosley Chistensen (Ed.) Industrial Dynamics of the New Digital Economy. Cheltenham, UK: Edward Elgar.

KERÉNYI, Á., MOLNÁR, J., \& MÜLLER, J. (2018). “Bank and FinTechs”. In: Economy and finance: English language edition of Gazdaság és Pénzügy, 5(1).

KON, Anita. (2016a). A Nova Economia Política dos Serviços. São Paulo: Perspectiva.

KON, A. (2016b). A economia do trabalho. Qualificação e segmentação no Brasil. Rio de Janeiro: Alta Books.

KON, João. (1998) “Recriando-se para a turbulência”, Revista RAE Light, FGV, São Paulo, Volume 5, N. 3 , jul/set.

LORENZ, E. N. (1996). A essência do caos. Brasília: Unib.

MAFRA, R. (2018). Aspectos jurídicos do processo de investimento em uma empresa inovadora. Rio de Janeiro: Couto Silva Advogados.

MAUERBERG Jr., A. (2013). “A complexidade e o construtivismo na economia”, em Revista de Economia Politica vol.33 no.3.

OLIVO, R. L. F. (2010). “Um estudo sobre a aplicação da teoria do caos e complexidade à gestão da cadeia de suprimentos”. São Paulo: FEA/USP. Dissertação de Mestrado.

PRIGOGINE, Ilya \& STENGERS, Isabelle. (1991). A nova aliança: metamorfose da Ciência, Brasília: Universidade de Brasília.

RONCARATTI, L. S. (2017). "Incentivos a startups no Brasil: os casos do Startup Brasil, InovAtiva e InovApps". Em CAVALCANTE, P. et al. Inovação no setor público : teoria, tendências e casos no Brasil. Brasília: Enap/ Ipea.

SANTOS, R. (2019). “As Consequências da Desindustrialização Brasileira no Desenvolvimento Econômico Nacional”. São Paulo: Seminários EITT/PUCSP.

SCHUMPETER, J. (1961) Capitalismo, socialismo e democracia. Rio de Janeiro: Fundo de Cultura.

VIANA, M. (2001). "Dynamical systems - moving into the next century”, in Björn Engquist, B. \& SCHMID, W. (Ed.) Mathematics Unlimited - 2001 and beyond. Berlin: Springer.

VILLELA, A. e CAVALCANTI, C. (1981). “Entropy: a new world view”. Em: Pesquisa e Planejamento Econômico - IPEA, Vol. 11 N. 2

VLAD, S.; PASCU, P, and MORARIU, N. (2010). "Chaos Models in Economics”. Journal of Computing, Volume 2, Issue 1.

WESTLUND, H., OLSSON, A. R. and LARSSO, J. P. (2011). Economic Entrepreneurship, Startups and Their Effects on Local Development: The Case of Sweden. Stockholm: Royal Institute of Technology. 